\title{
Pathophysiology of Late Onset Alzheimer Disease
}

\author{
Ahmet Turan Isik ${ }^{1}$ and M. Refik Mas ${ }^{2}$ \\ ${ }^{1}$ Bezmialem Vakif University, Faculty of Medicine, \\ Department of Geriatric Medicine, Istanbul, \\ 29 Eylul University, Faculty of Medicine, Department of Internal Medicine, Izmir
}

Turkey

\section{Introduction}

As the world population has aged, the number of people affected by Alzheimer Disease is rapidly increasing in the world. It is important for clinicians to recognize early signs and symptoms of dementia and to note potentially modifiable risk factors and early disease markers.

Accumulation of $\mathrm{A} \beta$ peptides may be the key event in pathogenesis of $\mathrm{AD}$. The exact mechanism by which $A \beta$ peptide deposition induces neurotoxicity is unclear, but it appears the oxidative stress plays an important role. Oxidative stress is extensive in AD and $A \beta$ peptides stimulate oxidative stress by both direct and indirect mechanisms. A $\beta$ peptides by themselves may act as enzymes and can bind to mitochondrial proteins resulting in the generation of free radicals. Furthermore, A $\beta$ peptides generate oxidative stress via neuroinflammation. Considerable evidence has supported that neuroinflammation is associated with $\mathrm{AD}$ pathology. In addition, in $\mathrm{AD}$, vascular injury and parenchymal inflammation perpetuate the cycle of protein aggregation and oxidation in the brain, and diffuse pathological changes include cerebral amyloid angiopathy, affecting more than $90 \%$ of patients with Alzheimer's disease, capillary abnormalities, disruption of the blood-brain barrier, and large-vessel. In addition, it was reported that clearance of $A \beta$ along diseased perivascular channels and through the blood-brain barrier is impeded in AD atheroma and that deregulation of $\mathrm{A} \beta$ transport across the capillary blood-brain barrier is caused by the imbalanced expression of low-density lipoprotein receptor-related proteins and receptors for advanced glycation end products. Besides, insulin resistance and hyperinsulinemia are implicated in a number of pathophysiological processes related to AD. It was demonstrated that reduced brain insulin signaling is associated with increased tau phosphorylation and $\mathrm{A} \beta$ levels in a streptozotocin induced model of diabetes mellitus. Moreover, insulin promotes the release of intracellular $A \beta$ in neuronal cultures and accelerates $A \beta$ trafficking to the plasma membrane. In addition, impaired insulin or insulin like growth factor-1 (IGF-1) signaling can result in the hyper-phosphorylation of tau, which can cause cell death mediated by apoptosis, mitochondrial dysfunction or necrosis and promote oxidative stress, which contributes to the neurodegeneration cascade and leads to dementia-associated behavioral and cognitive deficits. 
In shortly, the current pathophysiological approach to LOAD are based on a number of common mechanisms of neurodegeneration, such as accumulation of abnormal proteins, mitochondrial dysfunction and oxidative stress, impaired insulin signaling, calcium homeostasis dysregulation, early synaptic disconnection and late apoptotic cell death. Aging itself is associated with mild cognitive deterioration, probably due to subtle multifactorial changes resulting in a global decrease of a functional brain reserve.

\section{Pathophysiology of late onset Alzheimer disease}

As the world population has aged, dementia has become a common diagnosis in aging populations and the numbers will increase in the forthcoming years. Nowadays, the number of people affected by Alzheimer Disease (AD) is rapidly increasing in the world. AD is an age-related progressive neurodegenerative disorder presented by memory loss and severe cognitive decline (Isik \& Bozoglu, 2010).

$\mathrm{AD}$ is characterized by extensive atrophy of the brain caused by a series neuropathologic change, including neuronal loss, intracellular neurofibrillary tangles (NFTs) made up of Tau protein, extracellular senile plaques formed by $\beta$-amyloid $(\mathrm{A} \beta)$ and synaptic loss (Ballatore et al., 2007 \& Haass Selkoe, 2007). Amyloid plaques and NFT result from an aberration in deposition of the $A \beta$ peptide and the hyperphosphorylated tau protein, respectively, and these depositions lead to neuronal loss and neurotoxicity in the brain affected by AD (Isik, 2010). However, plaques and NFTs are not unique to AD, as these same structural changes occur with normal aging and in many others neurodegenerative disorders (Jackson-Siegal, 2005). Great confusion existed as to whether the dementia often observed in normal aging and $\mathrm{AD}$ were the same or different entities. It took nearly a century to define that the plaques were composed primarily of a specific peptide initially named A4 and today referred to as $A \beta$ and that tangles are composed primarily of hyperphosphorylated forms of tau, a microtubule-associated protein. Tau is a protein known to stabilize microtubules present primarily in axonal processes and involved in axonal transport of subcellular components. The abnormal phosphorylation of this microtubule-related protein leads to molecular protein structures called paired helical filaments (PHFs), which constitute the ultrastructural core of the microscopic structures recognized as NTFs. Most contemporary research on the molecular basis of the disease has focused chiefly on these two proteins, and the causality of the disease has been attributed to either or both of these proteins. For a while, the two camps of thought were humorously referred to as the Baptists (for $A \beta$ ) and the Taoists (for tau) (Cuello, 2007). A distinguishing feature of AD is that the plaques and NFTs are localized to areas in the brain corresponding to the clinical symptoms. Although the development of plaques and NFTs eventually leads to a noticeable clinical condition, the process is thought to start years before the initial onset of symptoms (Jackson-Siegal, 2005).

\section{Risk factors}

Great number of nongenetic risk factors have been identified or proposed for the sporadic form of the disease. Of these, unequivocally, aging is the most relevant. To define between the $\mathrm{AD}$ and aging, that $\mathrm{AD}$ might reflect a continuum of the brain aging can be proposed. In other words, given the opportunity, every individual should eventually succumb to AD. This view can be supported by the undeniable fact that aging is the most important of the nongenetic risk factors as shown by the ever growing incidence of $\mathrm{AD}$ with aging. On the 
other hand, the prevalent notion is that the incidence of $\mathrm{AD}$ is influenced by a multitude of risks factors in addition to aging, which might act in a cooperative manner. The extent of the life span could also be regulated by the genetic background interacting with environmental as well as lifestyle aspects. The role of genetics in determining the life span is complex and paradoxical. In short, the prevalent view is that for the sporadic form of AD, it is not necessarily all in the genes but rather interplay with the life experience of that particular individual. The molecular mechanisms of brain aging remain elusive. Several molecular events are suspects in the age-related downfall of brain function, which might be linked to the earlier appearance of AD. Some researchers have paid attention to low levels of vitamin $\mathrm{B}$ complex and the plasma elevation of homocysteine, as being responsible for age-related cognitive deficits and unleashing the AD pathology (Cuello, 2007). Furthermore, our results demonstrated that replacement and close follow up of vitamin B12 deficiency are crucial in the elderly population regardless of any disturbance in the hematological parameters (Bozoglu et al., 2010).

While early onset AD is almost genetically based, there are no specific gene mutations that are associated with inheritance of the disease in late onset AD (LOAD). The expression of the apolipoprotein $\mathrm{E}$ (ApoE) 4 allele is one of the risk factors identified for LOAD. In the central nervous system, ApoE is synthesized by astrocytes, microglia, and, to a lesser extent, by neurons. The role of ApoE in LOAD pathogenesis is not fully elucidated, but it has been suggested that ApoE is very important in trafficking of amyloid $\beta(\mathrm{A} \beta)$ peptide. In addition, apolipoprotein J (clusterin), an amyloid $\beta$-peptide chaperone, TOMM40, a transporter of proteins across the mitochondrial membrane, and Sortillin-related receptor, which functions to partition amyloid precursor protein away from $\beta$-secretase and $\gamma$-secretase, are recently discovered proteins encoded by the risk genes for LOAD. However, it was reported that higher plasma concentrations of clusterin correlate significantly with the presence and severity of AD but doesn't correlate with the risk for onset of the disease (Schrijvers et al, 2011).

In addition to nonmodifiable genetic risk factors, potentially modifiable factors, such as hypertension, diabetes mellitus, hyperlipidemia, hyperhomocysteinemia, coronary and peripheral artery diseases, alcohol, smoking, obesity, levels of physical or mental activity, levels of education, and environmental exposures have been investigated to identify risk factors for LOAD. Furthermore, it has been reported that risk index methods including these risk factors provide a practical, flexible, and objective framework for identifying the optimal combination of measures for identification of high-risk individuals for prevention and early intervention efforts. Despite the personal and social burden of LOAD, our understanding of the genetic predisposition to LOAD and the contribution of other risk factors remains limited. More importantly, there are few data to explain the overall risks and benefits of prevention strategies or their impact on risk modification (Isik, 2010; Querfurth \& La Ferla, 2010).

\section{Pathogenesis}

The amyloid material was initially thought to be systemically derived from serum proteins and characterized as a short peptide (9). A $\beta$ peptides are natural products of metabolism consisting of 36 to 43 amino acids. Monomers of $A \beta 40$ are more prevalent than the aggregation-prone and damaging $\mathrm{A} \beta 42$ species. $\beta$-amyloid peptides originate from proteolysis of the amyloid precursor protein (APP) lodged in cell membranes by the 
sequential enzymatic actions of beta-site amyloid precursor protein-cleaving enzyme 1 (BACE-1), a $\beta$-secretase, and $\gamma$-secretase, a protein complex with presenilin 1 at its catalytic core (Cuello, 2007). In this process the release of $A \beta$ peptides is achieved by the consecutive action of a $\beta$-secretase cleaving APP at the $N$-terminal site of the A $\beta$ domain, followed by its cleavage at the $\gamma$-secretase site at the $C$-terminal end, thus generating $A \beta$ fragments of diverse lengths, but typically of 40 and 42 amino acids in length. The longer peptide, A $\beta 1-$ 42 , is more neurotoxic and more prone to aggregation and amyloidogenic. The $\beta$ - and $\gamma$ secretases have been identified and cloned. Two proteins are currently recognized with $\beta$ secretase functions. They are named BACE 1 and 2, of which BACE 1 appears to be more important for the development of the AD pathology (Vassar \& Citron, 2000). The $\beta$ secretases release a large peptide which in biochemical jargon is referred to as C99, containing both the A $\beta$ motif and another motif defined as AICD (APP internal C-terminal domain). The $\gamma$-secretase site is more complex. Initially, it was proposed that presenilins (mutations of which were already known to cause familial forms of AD) were the actual $\gamma$ secretase. Today, there is consensus that the $\gamma$-secretase site is composed of an ensemble of proteins, some of which might be responsible for the modulation of the APP-catalytic activity preselinins 1 and 2 . This complex has the peculiarity of being capable of a catalytic action in the fairly hydrophobic milieu of cell and organelle membranes (Cuello, 2007).The catalytic activity of the $\gamma$-secretase action is ultimately responsible for the liberation of the amyloidogenic $A \beta$ peptide and the AICD fragment (Wolfe, 2006). AICD is suspected to either act as a transcription factor or be involved in cell signaling mechanisms in the CNS, however, its actual biological significance is still being debated (Cuello, 2007). Finally, an imbalance between production and clearance, and aggregation of peptides, causes $A \beta$ to accumulate, and this excess may be the initiating factor in Alzheimer's disease. This idea, called the "amyloid hypothesis," is based on studies of genetic forms of AD, including Down's syndrome, and evidence that A $\beta 42$ is toxic to cells (Querfurth \& La Ferla, 2010).

Amyloid plaques, together with NFTs, occur in $\mathrm{AD}$ and other neurodegenerative disorders, in addition to normal aging (Guillozet et al., 2003). The number of NFTs is a pathologic marker of the severity of AD. The major component of the tangles is an abnormally hyperphosphorylated and aggregated form of tau. Normally an abundant soluble protein in axons, tau promotes assembly and stability of microtubules and vesicle transport. Hyperphosphorylated tau is insoluble, lacks affinity for microtubules, and selfassociates into paired helical filament structures. Enzymes that add and those that remove phosphate residues regulate the extent of tau phosphorylation (8). These NFTs have a clear-cut temporal and topographic distribution across brain areas as the disease progresses. The best staging of such structures has been provided by Braak and Braak (Braak H\& Braak E, 1998). Interestingly, the earliest Braak stage is the occurrence of NFTs in the entorhinal cortex in the absence of an obvious deposition of $A \beta$ material in this brain region. This observation has been used as an argument to dissociate tau from $A \beta$ pathology in AD. The causal relation between these two molecular pathologies remains uncertain (Cuello, 2007).

The amyloid cascade hypothesis posits that $A \beta$ triggers Tau pathology, but the details of this relationship are still poorly understood. Accumulation of $A \beta$ peptides may be the key event in the pathogenesis of $\mathrm{AD}$ and experimental models have suggested that exposure of neurons to $A \beta$ is toxic and elicits abnormal changes in Tau (Garg et al., 2011). Although new imaging techniques and powerful animal models have helped understanding the time course and the mechanisms of the lesions, the relationship between $\mathrm{A} \beta$ accumulation and 
tau pathology is still badly understood and the mechanism of LOAD continues to be debated (4). In some studies, the changes in Tau were ascribed to a toxic Tau fragment of 17 $\mathrm{kD}$ generated by calpain cleavage and located in the N-terminal half of Tau, but other Nterminal parts of Tau were reported to be toxic as well. In these cases, the toxicity could be triggered by $A \beta$, but there was no apparent relationship to the aggregation of Tau. By contrast, studies on other cleavage reactions had shown that truncation of Tau in the $C$ terminal domain by caspase- 3 or by lysosomal proteases could generate Tau fragments with a high tendency for aggregation (Garg et al., 2011).

Data obtained by electron microscopy and immunocytochemical and biochemical analysis on synaptic marker proteins in AD biopsies and autopsies indicate that synaptic loss in the hippocampus and neocortex is an early event and the major structural correlate of cognitive dysfunction. From all cortical areas analyzed, the hippocampus appears to be the most severely affected by the loss of synaptic proteins, while the occipital cortex is affected least. Although the cause for this failure is still unknown, recent evidence indicates a link between plastic synaptic changes and control of differentiation and cell cycle-repression within a neuron (Arendt, 2009). In mild Alzheimer's disease, there is a reduction of about $25 \%$ in the presynaptic vesicle protein synaptophysin (Querfurth \& La Ferla, 2010) and there is evidence that living neurons lose their synapses in AD. Furthermore, synaptic function is impaired in living neurons, as demonstrated by decrements in transcripts related to synaptic vesicle trafficking (Coleman \& Yao, 2003).

The exact mechanism by which $A \beta$ peptide deposition induces neurotoxicity is unclear, but it appears that oxidative stress plays an important role. Besides, $A \beta$ is a potent mitochondrial poison, especially affecting the synaptic pool. In $A D$, exposure to $A \beta$ inhibits key mitochondrial enzymes in the brain and in isolated mitochondria. Cytochrome c oxidase is specifically attacked. Consequently, electron transport, ATP production, oxygen consumption, and mitochondrial membrane potential all become impaired (Querfurth \& La Ferla, 2010). Consequently, oxidative stress is extensive in AD, and $A \beta$ peptides stimulate oxidative stress by both direct and indirect mechanisms. $A \beta$ peptides by themselves may act as enzymes and can bind to mitochondrial proteins, resulting in the generation of free radicals (Lustbader et al., 2004; Newman et al., 2007) A $\beta$ peptides also generate oxidative stress via neuroinflammation. Considerable evidence has supported the hypothesis that neuroinflammation is associated with AD pathology (Newman et al., 2007).

Interestingly, $\mathrm{AD}$ was speculated as the brain equivalent of non-insulin-dependent diabetes mellitus (Hoyer, 1998; Craft et al., 2000). It was demonstrated that reduced brain insulin signaling is associated with increased tau phosphorylation and A $\beta$ levels in a Streptozotocin induced model of diabetes mellitus, and also insulin promotes the release of intracellular $A \beta$ in neuronal cultures and accelerates $A \beta$ trafficking to the plasma membrane. Similarly, Intravenous insulin infusion also raised plasma A $\beta 42$ levels in patients with AD but not in normal adults, an effect that was exaggerated in patients with AD with higher body mass indexes. In addition, impaired insulin or IGF-1 signaling can result in the hyper-phosphorylation of tau, which can cause cell death mediated by apoptosis, mitochondrial dysfunction or necrosis and promote oxidative stress, which contributes to the neurodegeneration cascade, and leads to dementia-associated behavioral and cognitive deficits. For this reason, it seems that insulin resistance causes Tau phosphorylation and neurofibrillary tangle formation and increased beta amyloid 
aggregation in late onset $\mathrm{AD}(1)$. In a recent study, Zhao and Townsend are demonstrated that insulin resistance and $\mathrm{A} \beta$ disrupt common signal transduction cascades including the insulin receptor family/Phosphoinositide 3-kinase/Akt/Glycogen synthase kinase3(GSK3) pathway. They reported that both disease processes contribute to overlapping pathology, thereby compounding disease symptoms and progression (Zhao \& Townsend, 2009). Besides, Proctor and Gray reported that GSK3 $\beta$ over activity leads to an increase in levels of $A \beta$ plaques and tau tangle (Weller et al., 2009). The age-associated decline in the metabolic rate and utilization of glucose by the frontal cortex imply that insulin resistance can cause executive dysfunctions in older people, not only global cognitive impairment. Insulin resistance may cause decreased cortical glucose utilization especially in hippocampus and entorhinal cortex and also increased oxidative stress with advanced glycation end-products. In humans, raising plasma insulin levels through intravenous infusion increased cerebrospinal fluid levels of the A $\beta 42$ peptide; this effect was exacerbated by age. That insulin may interfere with $A \beta$ degradation via its regulation of the metalloprotease insulin-degrading enzyme (IDE) may also be an important mechanism in late-onset $A D$ that the $A \beta$ clearance rather than $A \beta$ production may be of special importance. Actually, the A $\beta$-degrading capacity of IDE in the Alzheimer Disease brains is about $50 \%$ of that of control brains, but insulin degradation decreases by about $30 \%$ only. Decreased IDE mRNA and IDE activity have been found in the hippocampus of late-onset AD brains; however, in neurons adjacent to senile plaques, IDE is up-regulated (Isik \& Bozoglu, 2010).

Furthermore, in AD, vascular injury and parenchymal inflammation perpetuate the cycle of protein aggregation and oxidation in the brain, and diffuse pathologic changes include cerebral amyloid angiopathy, affecting more than $90 \%$ of patients with $\mathrm{AD}$, capillary abnormalities, disruption of the blood-brain barrier, and large-vessel channels (Querfurth \& La Ferla, 2010; Price et al., 2001). It has also been reported that clearance of $A \beta$ along diseased perivascular channels and through the blood-brain barrier is impeded in AD atheroma, (Deane \& Zlokovic, 2007) and that deregulation of $A \beta$ transport across the capillary blood-brain barrier is caused by the imbalanced expression of low-density lipoprotein receptor-related proteins and receptors for advanced glycation end products (Price et al., 2001; Proctor \& Gray 2010).

The calcium hypothesis of $\mathrm{AD}$ proposes that activation of the amyloidogenic pathway remodels the neuronal $\mathrm{Ca}(2+)$ signalling pathways responsible for cognition by enhancing the entry of $\mathrm{Ca}(2+)$ and/or the release of internal $\mathrm{Ca}(2+)$ by ryanodine receptors or $\operatorname{Ins} \mathrm{P}(3)$ receptors. The specific proposal is that $\mathrm{Ca}(2+)$ signalling remodelling results in a persistent elevation in the level of $\mathrm{Ca}(2+)$ that constantly erases newly acquired memories by enhancing the mechanism of long-term depression. Neurons can still form memories through the process of long term potentiation, but this stored information is rapidly removed by the persistent activation of long-term depression. Further dysregulation in $\mathrm{Ca}(2+)$ signalling will then go on to induce the neurodegeneration that characterizes the later stages of dementia (Berridge, 2010).

Finally, the current pathophysiologic approach to LOAD is based on a number of common mechanisms of neurodegeneration, including accumulation of abnormal proteins, mitochondrial dysfunction, and oxidative stress, impaired insulin signaling, calcium homeostasis dysregulation, early synaptic disconnection, and late apoptotic cell death. Aging itself is associated with mild cognitive deterioration, probably due to subtle multifactorial changes resulting in a global decrease of functional brain reserve. 


\section{References}

Arendt T (2009) Synaptic degeneration in Alzheimer's disease. Acta Neuropathol. 118:167179.

Ballatore C, Lee VM \& Trojanowski JQ (2007) Tau-mediated neurodegeneration in Alzheimer's disease and related disorders. Nat. Rev. Neurosci. 8: 663-672.

Berridge MJ (2010) Calcium Signalling and Alzheimer's Disease.Eur J Physiol. 459:441-449.

Braak H \& Braak E (1998) Argyrophilic grain disease: Frequency of occurrence in different age categories and neuropathological diagnostic criteria. Journal of Neural Transmission. 105:801-819.

Bozoglu E, Isik AT, Doruk H, Kilic S (2010) The Effects of Early Vitamin B12 Replacement Therapy on The Cognitive and Functional Status of Elderly Subjects. Bulletin of Clinical Psychopharmacology. 20:115-119.

Craft S, Asthana S, Schellenberg G \& et al. (2000) Insulin effects on glucose metabolism, memory, and plasma amyloid precursor protein in Alzheimer's disease differ according to apolipoprotein-E genotype. Ann NY Acad Sci. 903: 222-228.

Coleman PD \& Yao PJ (2003) Synaptic slaughter in Alzheimer's disease. Neurobiol Aging. 24:1023-1027.

Cuello AC (2007) Overview of the Alzheimer's Disease Pathology and Potential Therapeutic Targets. Eds: Cuello AC. Pharmacological Mechanisms in Alzheimer's Therapeutics, Springer, Canada, 1-27.

Deane R \& Zlokovic BV (2007) Role of the blood-brain barrier in the pathogenesis of Alzheimer's disease. Curr Alzheimer Res. 4:191-197.

Garg S, TimmT, Mandelkow E, Mandelkow E \& Wang Y (2011) Cleavage of Tau by calpain in Alzheimer's disease: the quest for the toxic $17 \mathrm{kD}$ fragment. Neurobiology of Aging. 32:1-14.

Glenner GG \& Wong CW (1984) Alzheimer's disease and Down's syndrome: Sharing of a unique cerebrovascular amyloid fibril protein. Biochemical and Biophysical Research Communications. 12:1131-1135.

Guillozet AL, Weintraub S, Mash DC \& Mesulam MM (2003) Neurofibrillary tangles, amyloid and memory in aging and mild cognitive impairment. Arch Neurol. 60:729-736.

Haass C \& Selkoe DJ (2007) Soluble protein oligomers in neurodegeneration: lessons from the Alzheimer's amyloid beta-peptide. Nat. Rev.Mol. Cell Biol. 8, 101-112

Hoyer S (1998) Is sporadic Alzheimer disease the brain type of non-insulin dependent diabetes mellitus? A challenging hypothesis. J Neural Transm. 105: 415-422.

Isik AT (2010) Late onset Alzheimer's disease in older people. Clinical Interventions in Aging. 5:307-311.

Isik AT \& Bozoglu E (2010) Chapter 20-Insulin resistance in Alzheimer disease: Eds: Aucoin L, Prideux T:Handbook of Type 1 Diabetes Mellitus: Etiology, Diagnosis, and Treatment, Nova Science, Hauppauge NY.

Jackson-Siegal J (2005) Our current understanding of the pathophysiology of Alzheimer's Disease. Adv Stud Pharm. 2(4):126-135.

Lustbader JW, Cirilli M \& Lin C (2004) ABAD directly links Abeta to mitochondrial toxicity in Alzheimer's disease. Science. 304:448-452.

Newman M, Musgrave FI \& Lardelli M (2007) Alzheimer disease: Amyloidogenesis,the presenilins and animal models. Biochimica Biophysica Acta. 1772:285-297. 
Querfurth HW \& La Ferla FM (2010) Mechanisms of Disease:Alzheimer's Disease. N Engl J Med. 362;4:329-344.

Price JM, Chi X, Hellermann G \& Sutton ET (2001) Physiological levels of beta-amyloid induce cerebral vessel dysfunction and reduce endothelial nitric oxide production. Neurol Res. 23:506-512.

Proctor CJ \& Gray DA (2010) GSK3 and p53 is there a link in Alzheimer's disease? Molecular Neurodegeneration. 5(7);1-15.

Schrijvers EM, Koudstaal PJ, Hofman A \& Breteler MM (2011) Plasma clusterin and the risk of Alzheimer Disease. JAMA. 305:1322-1326.

Vassar R \& Citron M (2000) Abeta-generating enzymes: Recent advances in beta and gamma-secretase research. Neuron. 27:419-422.

Weller RO, Boche D \& Nicoll JAR (2009). Microvasculature changes and cerebral amyloid angiopathy in Alzheimer's disease and their potential impact on therapy. Acta Neuropathol. 118:87-102.

Wolfe MS (2006) The gamma-secretase complex: Membrane-embedded proteolytic ensemble. Biochemistry. 45:7931-7939.

Zhao WQ \& Townsend M (2009) Insulin resistance and amyloidogenesis as common molecular foundation for type 2 diabetes and Alzheimer's disease. Biochimica et Biophysica Acta, 1792: 482-496. 


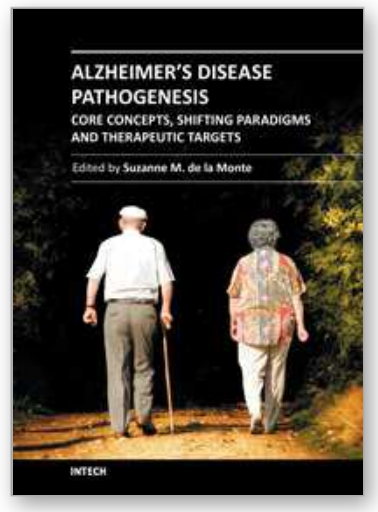

\author{
Alzheimer's Disease Pathogenesis-Core Concepts, Shifting \\ Paradigms and Therapeutic Targets \\ Edited by Dr. Suzanne De La Monte
}

ISBN 978-953-307-690-4

Hard cover, 686 pages

Publisher InTech

Published online 12, September, 2011

Published in print edition September, 2011

Alzheimer's Disease Pathogenesis: Core Concepts, Shifting Paradigms, and Therapeutic Targets, delivers the concepts embodied within its title. This exciting book presents the full array of theories about the causes of Alzheimer's, including fresh concepts that have gained ground among both professionals and the lay public. Acknowledged experts provide highly informative yet critical reviews of the factors that most likely contribute to Alzheimer's, including genetics, metabolic deficiencies, oxidative stress, and possibly environmental exposures. Evidence that Alzheimer's resembles a brain form of diabetes is discussed from different perspectives, ranging from disease mechanisms to therapeutics. This book is further energized by discussions of how neurotransmitter deficits, neuro-inflammation, and oxidative stress impair neuronal plasticity and contribute to Alzheimer's neurodegeneration. The diversity of topics presented in just the right depth will interest clinicians and researchers alike. This book inspires confidence that effective treatments could be developed based upon the expanding list of potential therapeutic targets.

\title{
How to reference
}

In order to correctly reference this scholarly work, feel free to copy and paste the following:

Ahmet Turan Isik and M. Refik Mas (2011). Pathophysiology of Late Onset Alzheimer Disease, Alzheimer's Disease Pathogenesis-Core Concepts, Shifting Paradigms and Therapeutic Targets, Dr. Suzanne De La Monte (Ed.), ISBN: 978-953-307-690-4, InTech, Available from: http://www.intechopen.com/books/alzheimers-disease-pathogenesis-core-concepts-shifting-paradigms-and-therapeutic-targets/pathophysiology-of-lateonset-alzheimer-disease

\section{INTECH}

open science | open minds

\section{InTech Europe}

University Campus STeP Ri

Slavka Krautzeka 83/A

51000 Rijeka, Croatia

Phone: +385 (51) 770447

Fax: +385 (51) 686166

www.intechopen.com

\section{InTech China}

Unit 405, Office Block, Hotel Equatorial Shanghai

No.65, Yan An Road (West), Shanghai, 200040, China 中国上海市延安西路65号上海国际贵都大饭店办公楼 405 单元

Phone: +86-21-62489820

Fax: +86-21-62489821 
(C) 2011 The Author(s). Licensee IntechOpen. This chapter is distributed under the terms of the Creative Commons Attribution-NonCommercialShareAlike-3.0 License, which permits use, distribution and reproduction for non-commercial purposes, provided the original is properly cited and derivative works building on this content are distributed under the same license. 